\title{
RESONANCE POTENTIALS AND LOW-VOLTAGE ARCS FOR METALS OF THE SECOND GROUP OF THE PERIODIC TABLE
}

\author{
By F. L. Mohler, Paul D. Foote, and W. F. Meggers
}

\section{INTRODUCTION.}

Most of the knowledge of the relation between line spectra and electron collisions is based on the study of the phenomena of electron currents in vapors of metals of the first and second groups of the periodic table. Critical potentials for resonance and ionization collisions have been observed for nine of these metals. ${ }^{1}$

Arc spectra below the ionization potential have been studied for six of these elements. ${ }^{2}$

The investigation of the low-voltage arc spectrum of cæsium, by Foote and Meggers, together with the data on critical potentials for all the alkali metals except lithium, give a certain basis for the following conclusions concerning this group. Electrons having a velocity less than that acquired by falling through the resonance potential, collide elastically with molecules. Impacts with velocity greater than this are inelastic, and the velocity lost by the electron is equivalent in volts to this potential. The resonance potential is given by the quantum relation $\mathrm{V} e=h \nu$, where $\nu$ is the frequency of the first line of the principal series; and the quantum of energy lost by the electron is radiated as light of this single frequency. Molecules may be ionized by collision when the impacting electron has a velocity exceeding a second higher potential. This ionization potential is given by the quantum relation when $\nu$ is the limiting frequency of the

\footnotetext{
${ }^{1}$ Mercury: Franck and Hertz,Verh D. Phys. Ges., 16, p. 457, I9i4; also Tate, Phys. Rev., 7, p. 686, I9I6. Cadmium, zinc, sodium, and potasium: Tate and Foote, Phil. Mrag., 36, p. 64 ; 1918.

Arsenic, rubidium, and cæsium: Foote, Rognley, and Mohler, Phys. Rev., 13, p. 59; I919. Magnesium and thalium: Foote and Mohler, Phil. Mag., 37, p. 33; 19r9.

Calcium and lead: Mohler, Foote, and Stimson, B. S., Sci. Papers, No. 368 ; 1920.

2 Mercury: Franck and Hertz, Verh D. Phys. Ges., 16, p. 512; xgr4.

Mercury, zinc, and cadmium: McLennan and Henderson, Proc. Roy. Soc., A91, p. 485; 1915. Magnesium: McLennan, Proc. Roy Soc., A92, p. 574; 19r6.

Zinc and cadmium: McLennan and Ireton, Phil. Mag., 36, p. 46r; r9r8.

Sodium: Wood and Okano, Phil. Mag., 34, p. I77, I917; also, Foote and Mohler, Jour. Wash. Acad. Sci.,

8, p. $51_{3} ;$ igr 8 .

Cæsium: Foote and Meggers, Phil. Mag., 40, p. 80; 1920.
} 
principal series. Above this potential the entire line spectrum appears. This light emission is probably caused by recombination of electrons and ionized molecules and the energy involved is not received directly from electron impacts.

While the phenomenon of successive inflections in the current voltage curve, corresponding to successive resonance collisions, shows that in this case the transfer of energy is by quanta, there is no corresponding evidence for ionization collisions. It is entirely in accord with atomic theories that this latter energy transfer should not be by quanta. Thus when an electron with velocity exceeding the ionization potential ejects an electron from an atom it may divide its remaining energy with the ejected electron, so that the greater its energy before collision the greater will be its loss of energy.

The phenomena of electron currents in metals of the second group are similar, but the relations to spectral frequencies are more complicated. Their spectra show three groups of series: Single line, doublet and triplet series, and combination series, made up of single series and triplet series terms. Previous work has shown in all these metals a resonance potential given by the frequency of the combination series line $1.5 S-2 p_{2}$ (Paschen notation) and an ionization potential given by the limiting frequency 1.5 $S$. In calcium a second resonance potential was observed corresponding to the frequency of the first line of the principal series of single lines, I.5 $S-2 P$; a series having the same limit as the combination series.

Spectroscopic studies of the low-voltage arcs have shown the line $1.5 S-2 p_{2}$ below the ionization potential in mercury, zinc, and cadmium. The line $1.5 S-2 P$ was also observed above a potential corresponding to its frequency in zinc and cadmium, but in magnesium this line alone was observed by McLennan below the ionization point. Measurements of the photo-electric effect of radiation from the low-voltage mercury arc ${ }^{3}$ give evidence that both mercury lines appear at their corresponding potentials. The failure to observe the line of higher frequency spectroscopically is accounted for by its position in the extreme ultra-violet. The failure to observe the line $1.5 S-2 p_{2}$ at $\lambda=457$ I A in magnesium offers, however, a real difficulty in explaining the relation between resonance potentials and low-voltage arcs. This and the possibility of detecting two resonance potentials in metals other than calcium led to the present work. 


\section{METHODS OF MEASURING RESONANCE POTENTIALS}

Previous measurements were made in three-electrode tubes consisting of a Wehnelt cathode surrounded by a grid and plate in the form of concentric cylinders. Potentials of inelastic impact were observed by fixing a small retarding field between the grid and plate and measuring the electron current reaching the plate for different values of the accelerating field between the cathode and grid. Most of the collisions with molecules occurred in the space in which the electrons were accelerated so that with high vapor pressure the electron velocity would never much exceed the first resonance potential. Curves obtained under these conditions show a long series of sharp inflections in the current voltage curve at intervals equal to the first resonance potential (see Fig. $\mathrm{IC}$ ), due to electrons undergoing successive resonance collisions, but inelastic collisions due to any higher resonance potentials are entirely masked.

The four-electrode tube as developed for measurement of critical potentials in nonmetallic gases and vapors ${ }^{4}$ is much more sensitive for the detection of secondary resonance potentials. In this tube there are two grids, one close to the cathode and the other close to the plate. For sensitive indication of inelastic impact the two grids are kept at the same potential by metallic contact, the variable accelerating field is between the cathode and inner grid, and the retarding field between the outer grid and plate. Under these conditions, through a considerable range of vapor pressure, electrons will receive the full velocity corresponding to the accelerating potential before colliding with molecules in the larger part of their path between the nets. The type of curve obtained with a three-electrode tube can be secured with the four-electrode tube by applying a small constant accelerating potential between the cathode and inner grid; the variable accelerating potential between the grids; and, as before, measuring the current reaching the plate against a small retarding field.

Ionization can be measured by the Lenard method, viz, by making the retarding potential greater than the accelerating and noting the accelerating potential required to cause a current due to positive ions to flow between the outer grid and plate. Ionization measurements were only occasionally made as a check, since there is no reason to question the results on this point previously obtained.

4 Mohler and Foote, B. S. Scientific Paper and Jour. Amer. Opt. Soc., 4, p. 49; 1920. 
The ionization chamber was of cylindrical form with the grid and plate surrounding the cathode. In the experiments with mercury, platinum electrodes were sealed in a glass tube. In some of this work the cathode was an equipotential surface, but for the most part a platinum strip cathode coated with oxide was used. A coated molybdenum wire was employed with magnesium. With the metals of higher boiling point than mercury, the other electrodes were of nickel sheet and gauze. These were suspended in a large Pyrex tube from a metal plate sealed in with wax. The tubes were heated in an electric furnace and vacuum of less than o.oor $\mathrm{mm} \mathrm{Hg}$ maintained by mercury-vapor pumps.

\section{RESULTS OF CURRENT-POTENTIAL MEASUREMENTS}

The experiments with mercury vapor were much more extensive than with the other metals. Several designs of tube and methods

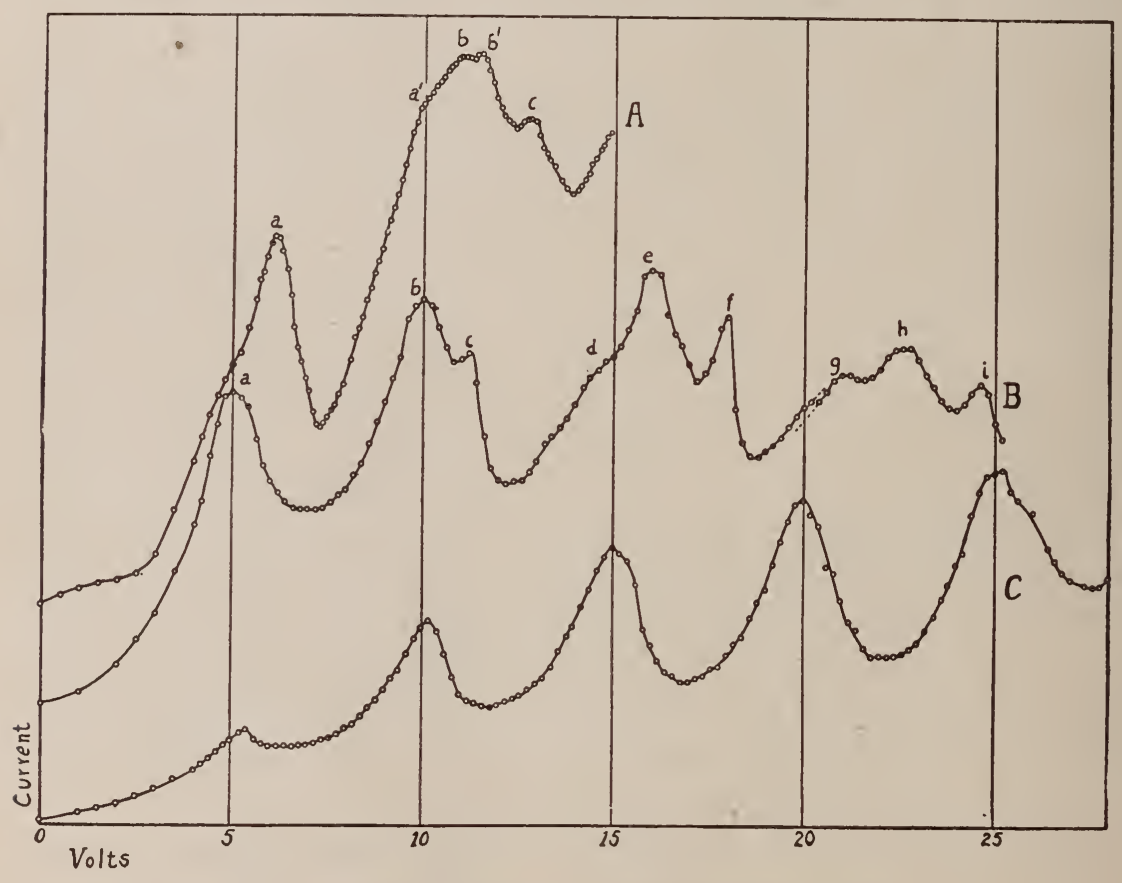

FIG. I.-Current-voltage curves in mercury vapor

of measurement were tried, but the method first described was found to be the most sensitive, while changes in design, such as substituting a simple hot wire cathode for an equipotential source, gave no marked difference in results. Fig. I shows three typical curves, while Table I gives the critical potentials for all curves. Curve $A$ was obtained with a low vapor pressure, curve $B$ at higher temperature and pressure, and curve $C$ with much higher vapor 
pressure and with the electrodes connected by the second method described. This last curve is very similar to the type obtained with a three-electrode tube and shows inflections only at intervals of 4.9 volts. It is included for purposes of comparison and is not listed in the table. The curves obtained under the other conditions show clearly the existence of other critical points than the resonance at 4.9 volts and ionization at 0.3 volts.

TABLE 1.-Data from Current Voltage Curves in Mercury

\begin{tabular}{|c|c|c|c|c|c|c|c|c|c|c|c|}
\hline \multirow{2}{*}{ Curve } & \multicolumn{11}{|c|}{ Applied potentials at points of inflection } \\
\hline & a & $a^{\prime}$ & b & $\mathbf{b}^{\prime}$ & c & d & e & f & $g$ & $\mathrm{~h}$ & i \\
\hline 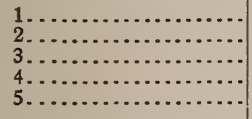 & $\begin{array}{l}6.0 \\
5.9 \\
6.0 \\
6.2 \\
6.3\end{array}$ & $\begin{array}{r}9.2 \\
9.9 \\
10.1 \\
10.0 \\
10.5\end{array}$ & $\begin{array}{l}10.7 \\
10.9 \\
10.9 \\
10.8 \\
11.3\end{array}$ & $\begin{array}{l}11.5 \\
11.4 \\
11.5 \\
11.8\end{array}$ & $\begin{array}{r}12.2 \\
12.6 \\
12.6 \\
12.9 \\
\cdots\end{array}$ & $\begin{array}{r}15.4 \\
15.4 \\
15.5 \\
\cdots \\
15.5\end{array}$ & $\begin{array}{r}17.2 \\
17.6 \\
17.8 \\
\cdots 17.8\end{array}$ & $\begin{array}{c}19.0 \\
20.2 \\
19.6 \\
19.8\end{array}$ & 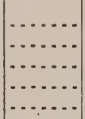 & $\begin{array}{l}\cdots \\
\cdots \\
\cdots \\
\cdots \\
\cdots\end{array}$ & 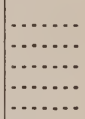 \\
\hline 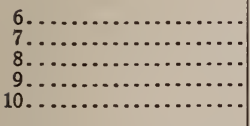 & $\begin{array}{l}6.1 \\
6.2 \\
5.4 \\
5.4 \\
5.5\end{array}$ & 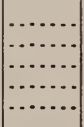 & $\begin{array}{l}10.9 \\
11.1 \\
10.3 \\
10.3 \\
10.3\end{array}$ & 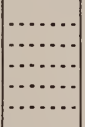 & $\begin{array}{l}12.6 \\
12.7 \\
11.8 \\
11.6 \\
11.8\end{array}$ & $\begin{array}{r}15.7 \\
15.6 \\
\cdots \\
\cdots .7 . \\
14.7\end{array}$ & $\begin{array}{r}17.4 \\
17.2 \\
\cdots \cdots \\
\cdots \\
16.2\end{array}$ & $\begin{array}{c}19.2 \\
19.6 \\
\cdots \ldots . \\
\cdots \cdots \\
\cdots\end{array}$ & $\mid \begin{array}{l}\ldots \ldots \\
\cdots \\
\cdots \\
\cdots \\
\cdots \\
\cdots\end{array}$ & 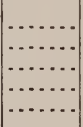 & $\mid \begin{array}{l}\cdots \ldots \\
\cdots \\
\cdots \\
\cdots\end{array}$ \\
\hline $\begin{array}{l}11 \\
12 \ldots \ldots \ldots \\
13 \\
14 \\
15 \\
15\end{array}$ & $\begin{array}{l}5.4 \\
5.1 \\
5.0 \\
5.0 \\
4.9\end{array}$ & 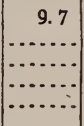 & $\begin{array}{r}10.3 \\
9.9 \\
10.0 \\
10.0 \\
9.9\end{array}$ & $\mid \begin{array}{l}\ldots \ldots \\
\cdots \ldots \\
\cdots \\
\cdots\end{array}$ & $\begin{array}{l}11.8 \\
11.3 \\
11.4 \\
11.3 \\
11.3\end{array}$ & $\begin{array}{c}\cdots \\
14.4 \\
\cdots \\
\cdots\end{array}$ & $\begin{array}{l}16.4 \\
16.2 \\
16.2 \\
16.0 \\
16.0\end{array}$ & $\begin{array}{r}18.2 \\
18.2 \\
\cdots 17.7\end{array}$ & 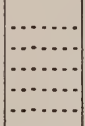 & 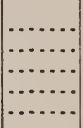 & \begin{tabular}{|l}
$\ldots \ldots \ldots$ \\
$\cdots \ldots \ldots$ \\
$\cdots \ldots \ldots$ \\
$\cdots \ldots \ldots$
\end{tabular} \\
\hline 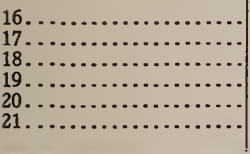 & $\begin{array}{l}4.8 \\
4.8 \\
5.5 \\
5.6 \\
5.5 \\
5.2\end{array}$ & 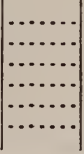 & $\begin{array}{r}9.7 \\
9.7 \\
10.4 \\
10.4 \\
10.5 \\
10.1\end{array}$ & 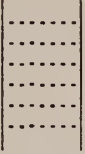 & $\begin{array}{l}11.2 \\
11.2 \\
11.7 \\
11.8 \\
12.4 \\
11.6\end{array}$ & $\mid \begin{array}{r}\cdots \\
14.3 \\
17.8 \\
15.2 \\
\cdots\end{array}$ & $\begin{array}{l}15.9 \\
15.8 \\
16.4 \\
16.4 \\
16.8 \\
16.5\end{array}$ & $\begin{array}{l}17.7 \\
17.8 \\
18.3 \\
18.5 \\
18.8 \\
18.2\end{array}$ & $\begin{array}{r}21.0 \\
20.8 \\
\cdots \cdots \\
\cdots \cdots . . . \\
\cdots \cdots\end{array}$ & $\begin{array}{r}22.6 \\
22.4 \\
\cdots \cdots \\
\cdots \cdots . . \\
23.0\end{array}$ & $\begin{array}{r}\ldots . .5 \\
\cdots \cdots \\
\cdots \cdots\end{array}$ \\
\hline \multirow[b]{2}{*}{ Curve } & \multicolumn{10}{|c|}{ Resonance potentials } & Ioniza- \\
\hline & $\mathrm{b}-\mathrm{a}$ & $c-a$ & $d-b$ & $e-b$ & $e-c$ & $\mathrm{f}-\mathrm{c}$ & $\mathrm{g}-\mathrm{e}$ & h-e & $\mathrm{i}-\mathrm{f}$ & $a^{\prime}-a$ & $\begin{array}{c}\text { minus } \\
\text { reso- } \\
\text { nance, } \\
\mathbf{b}^{\prime}-\mathbf{a}\end{array}$ \\
\hline 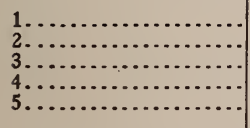 & $\begin{array}{l}\text { 4. } 7 \\
5.0 \\
4.9 \\
4.6 \\
5.0\end{array}$ & $\begin{array}{r}6.2 \\
6.7 \\
6.6 \\
6.7 \\
\cdots\end{array}$ & $\begin{array}{r}4.7 \\
4.5 \\
4.6 \\
4.2\end{array}$ & $\begin{array}{r}6.5 \\
6.4 \\
6.9 \\
6.5\end{array}$ & $\begin{array}{r}5.0 \\
4.7 \\
5.2 \\
-. . . \\
-\end{array}$ & $\begin{array}{r}6.8 \\
7.6 \\
7.0 \\
\cdots \cdots \\
\cdots \\
\cdots\end{array}$ & $\begin{array}{l}\cdots . . \\
\ldots . . \\
\cdots . . \\
\cdots . .\end{array}$ & & & \begin{tabular}{l|}
3.2 \\
4.0 \\
4.1 \\
3. 8 \\
4.2
\end{tabular} & $\begin{array}{r}5.6 \\
5.4 \\
5.3 \\
5.5\end{array}$ \\
\hline 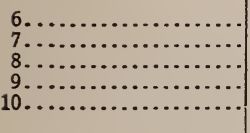 & $\begin{array}{l}4.8 \\
4.9 \\
4.9 \\
4.9 \\
4.8\end{array}$ & $\begin{array}{l}6.5 \\
6.5 \\
6.4 \\
6.2 \\
6.3\end{array}$ & $\begin{array}{r}4.8 \\
4.5 \\
\cdots \\
\cdots . .4 \\
4.4\end{array}$ & $\begin{array}{r}6.5 \\
6.1 \\
\cdots . . . \\
5.9\end{array}$ & $\begin{array}{r}4.8 \\
4.5 \\
-. .7 \\
4.4\end{array}$ & $\begin{array}{r}6.6 \\
6.9 \\
\cdots \\
\cdots\end{array}$ & 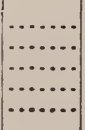 & & 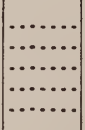 & 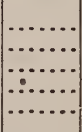 & $\mid \begin{array}{l}\ldots \ldots \\
\cdots \ldots \\
\cdots \\
\cdots\end{array}$ \\
\hline $\begin{array}{l}11, \ldots \ldots \ldots \\
12 \\
13 \\
14 \ldots \ldots \\
15 \\
15 \ldots \ldots\end{array}$ & $\begin{array}{l}4.9 \\
4.8 \\
5.0 \\
5.0 \\
5.0\end{array}$ & $\begin{array}{l}6.4 \\
6.2 \\
6.4 \\
6.3 \\
6.4\end{array}$ & $\begin{array}{r}\ldots \ldots \\
\ldots \ldots \\
\ldots \ldots \\
\ldots \ldots \\
\ldots \ldots\end{array}$ & $\begin{array}{l}6.1 \\
6.3 \\
6.2 \\
6.0 \\
6.1\end{array}$ & $\begin{array}{l}4.6 \\
4.9 \\
4.8 \\
4.7 \\
4.7\end{array}$ & $\begin{array}{r}6.9 \\
6.8 \\
6.4\end{array}$ & $\mid$\begin{tabular}{|l|}
$\cdots$ \\
$\ldots \ldots$ \\
$\cdots$ \\
$\cdots$ \\
$\cdots$
\end{tabular} & & 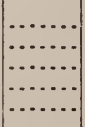 & 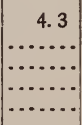 & $\begin{array}{l}\cdots \ldots \\
\ldots \ldots \\
\cdots \\
\cdots \\
\cdots\end{array}$ \\
\hline 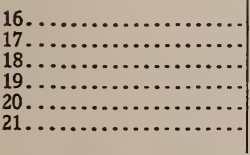 & $\begin{array}{l}4.9 \\
4.9 \\
4.9 \\
4.8 \\
5.0 \\
4.9\end{array}$ & $\begin{array}{l}6.4 \\
6.4 \\
6.2 \\
6.2 \\
6.9 \\
6.4\end{array}$ & $\begin{array}{r}\not .0 .6 \\
4.4 \\
4.7 \\
\cdots\end{array}$ & $\begin{array}{l}6.2 \\
6.1 \\
6.0 \\
6.0 \\
6.3 \\
6.4\end{array}$ & $\begin{array}{l}4.7 \\
4.6 \\
4.6 \\
4.4 \\
4.4 \\
4.9\end{array}$ & $\begin{array}{l}6.5 \\
6.6 \\
6.7 \\
6.4 \\
6.4 \\
6.6\end{array}$ & 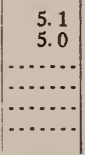 & $\begin{array}{r}6.7 \\
6.6 \\
\cdots . . . \\
\cdots \cdots . . \\
\cdots .5\end{array}$ & \begin{tabular}{r|}
$\cdots .7$ \\
6.7. \\
$\cdots$ \\
$\cdots$
\end{tabular} & $\mid \begin{array}{l}\cdots \cdots \\
\cdots \cdots \\
\cdots \cdots \\
\cdots \cdots \\
\cdots \cdots \\
\ldots\end{array}$ & 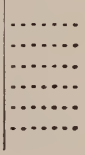 \\
\hline
\end{tabular}

First resonance potential mean of $b-a, d-b, e-c$, and $g-e=4.76$ volts. 
All the points of inflection on curves of the type $B$ can be explained by the superposed effect of two resonance potentials at intervals of 4.9 volts and 6.7 volts, approximately. Inflections marked $a, b$, and $d$ are due to one, two, and three successive collitions of the first type; $c$ is due to successive collisions of one of the first and one of the second types in either order; $e$, two of the first and one of the second; $f$, one of the first and two of the second; $g$, three of the first and one of the second; $h$, two of the first and two of the second; and $i$, one of the first and three of the second. Curves of type $A$ with very low vapor pressure show two additional points. The inflection $b^{\prime}$ is at the ionization point, while the faint but rather definite inflection $a^{\prime}$ gives evidence of a third resonance potential at 8.7 volts. Increasing the vapor pressure makes both these points indistinguishable.

The failure to observe an inflection due to one resonance collision of the second type is of interest. Undoubtedly the probability of a resonance collision of the second type is smaller than the first, and the strong inflection due to the latter entirely masks the effect of the former. Some curves show evidence of the second point, but never sharp enough for measurement. In the paper by Mohler, Foote, and Stimson on "Lead and Calcium," the type of curve to be expected when there are two resonance potentials has been discussed. Overlapping effects of successive inflections reduce the accuracy attainable. Possibly slight inflections due to successive collisions involving the ionization potential or a third resonance potential complicate some of the curves, but, as seen in the table, the two resonance potentials suffice to explain nearly all the points observed. The mean values are:

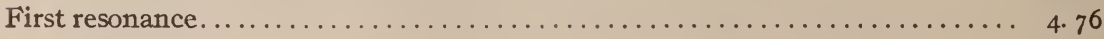

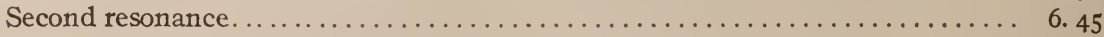

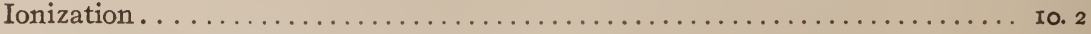

Possible third resonance $\ldots \ldots \ldots \ldots \ldots \ldots \ldots \ldots \ldots \ldots \ldots \ldots \ldots \ldots \ldots \ldots \ldots \ldots \ldots$ 8. 7

The two low-voltage arc lines and the limiting frequency of the two series involved give the following theoretical values for the first three potentials:

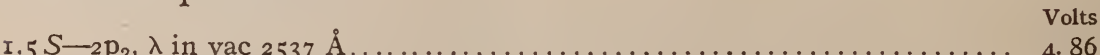

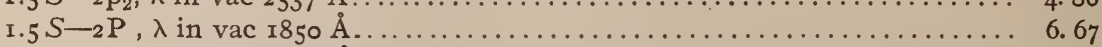

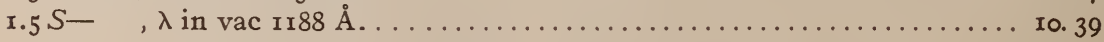

As to the point observed at 8.7 volts, the second lines of either of the two absorption series which determine the other critical points fall within observational error of this value. They are:

$$
\begin{array}{lll}
\text { I. } 5 S-3 \mathrm{P}_{2}, & \lambda=\mathrm{I} 435.55 & V=8.60 \text { volts } \\
\text { I.5 } S-3 \mathrm{P}, & \lambda=\mathrm{I} 402.7 \mathrm{I} & V=8.80 \text { volts }
\end{array}
$$


That either or both of these frequencies should give rise to resonance collisions is in accord with the Bohr atomic model. However, Foote and Meggers, ${ }^{5}$.in their paper on low-voltage arcs in cæsium, gave experimental evidence showing in that case, resonance potentials corresponding to higher frequencies of the absorption series than the first line did not exist. The authors believe that the evidence here given is insufficient to prove that the contrary is the case with metals of the second group. Further information in this regard requires a spectroscopic investigation.

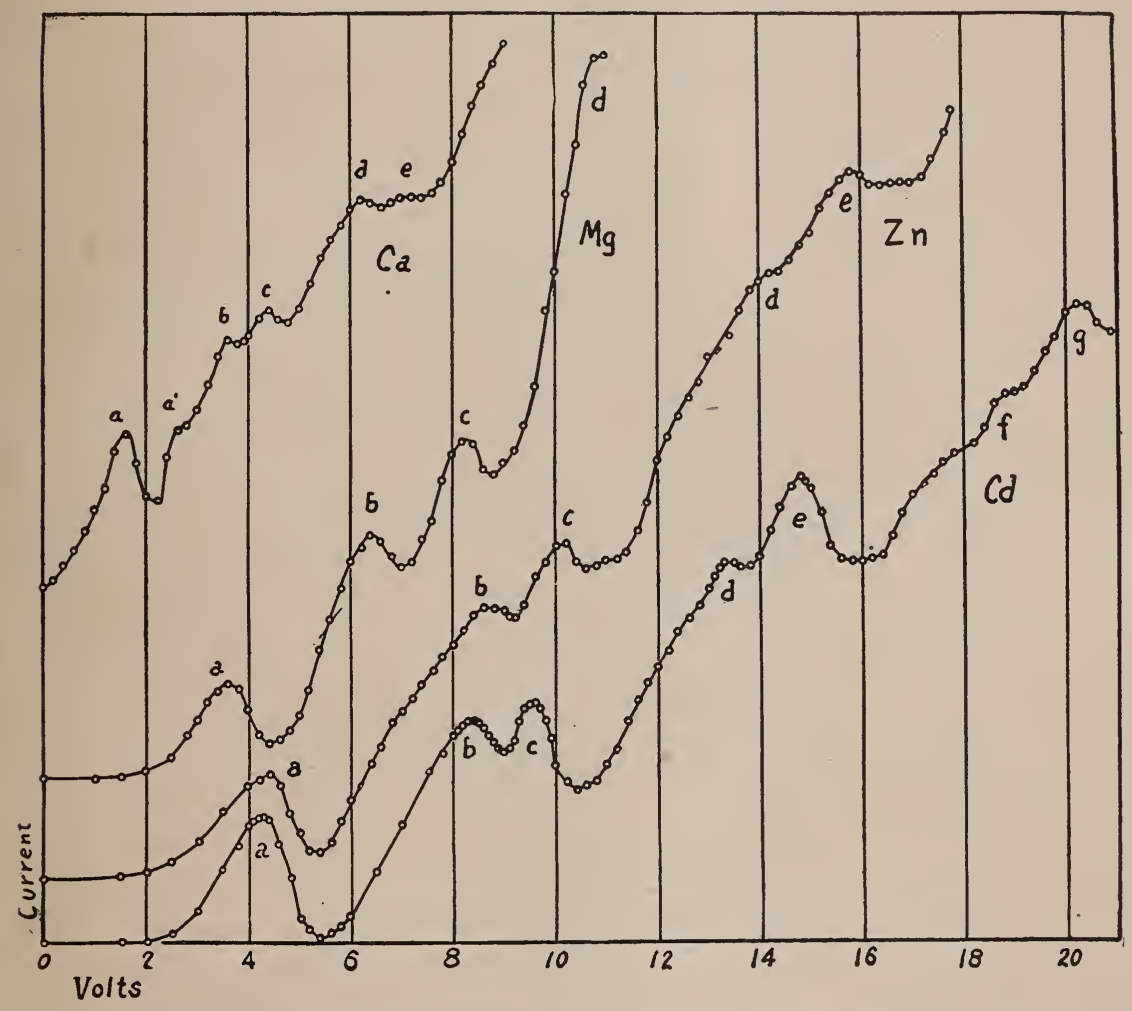

Fig. 2.-Current=voltage curves in vapors of cadmium, zinc, magnesium, and calcium

The accuracy obtainable in the measurements of the lowest potential of inelastic impact from curves of type $C$ is much higher than that shown by the above results. This curve gives for the interval between the first and fifth inflection $19.5 \pm 0.2$ volts, giving the resonance potential as $4.88 \pm 0.5$ volts, theoretical value 4.865 volts.

Curves for the metals cadmium, zinc, and magnesium are given in Fig. 2. A curve for calcium as obtained in a three-electrode tube 
from the work of Mohler, Foote, and Stimson ${ }^{6}$ is added for completeness. Tables 2, 3, and 4 give all the data obtained with the first three metals.

TABLE 2.-Data from Current-Voltage Curves in Cadmium

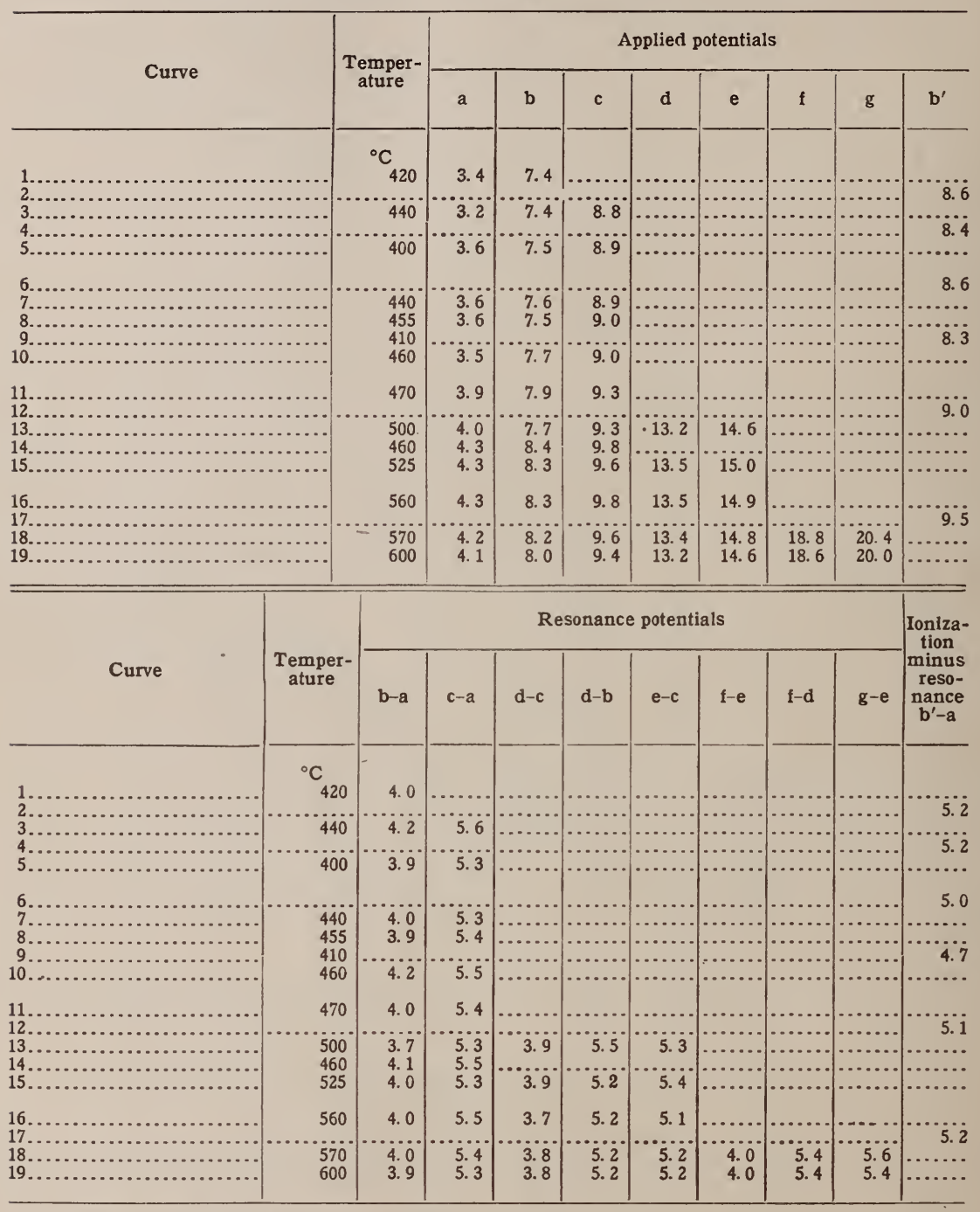

First resonance potentiai mean of $b-a, d-c$, and $f-e=3.95$ volts.

Second resonance potential mean of $c-a, d-b, e-c, f-d$, and $g-e=5.35$ volts.

Ionization potential $b^{\prime}-a+$ first resonance potential $=9.0$ volts. 
TABLE 3.-Data from Current-Voltage Curves in Zinc

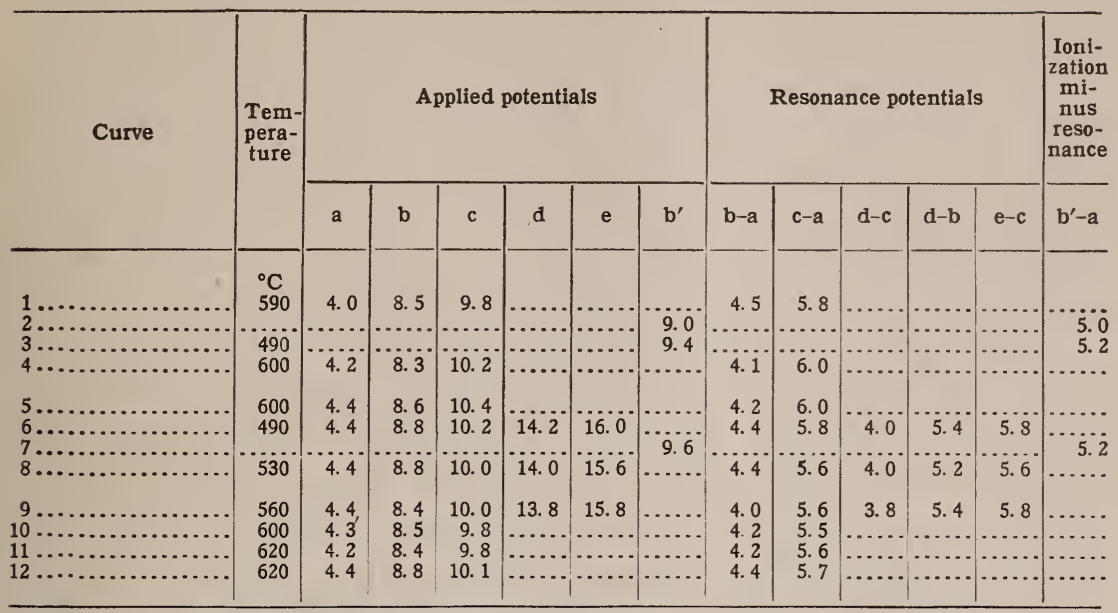

First resonance potential mean of $b-a$ and $d-c=4.18$ volts.

Second resonance potential mean of $c-a, d-b$, and $e-c=5.65$ volts.

Ionization potential $\left(b^{\prime}-a\right)+$ first resonance potential $=9.3$ volts.

TABLE 4.-Data from Current-Voltage Curves in Magnesium

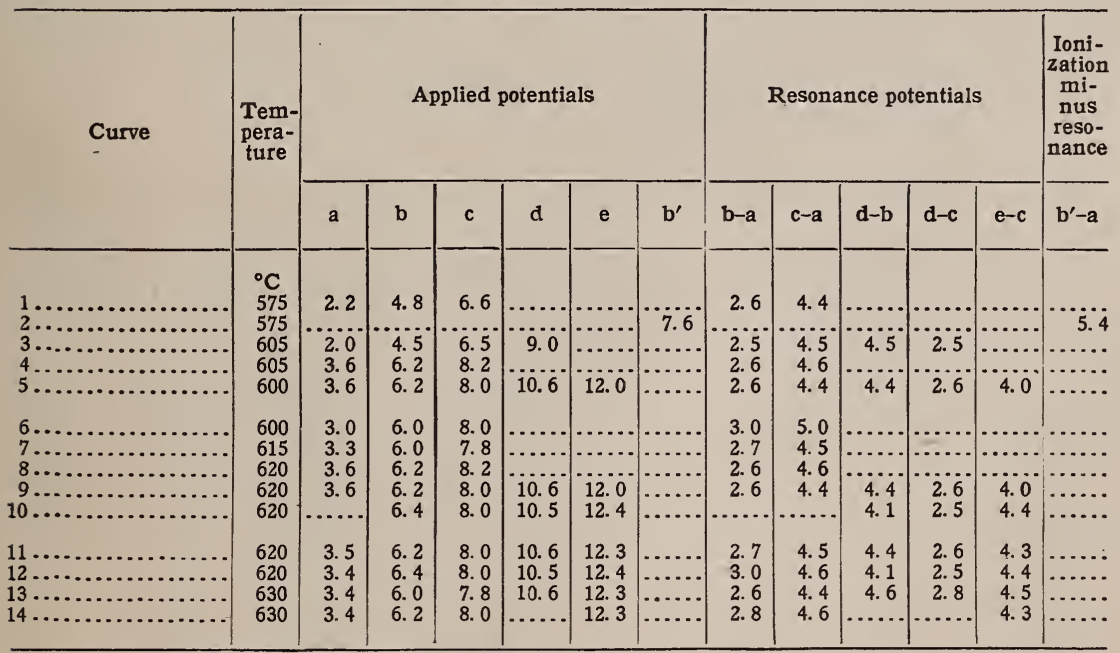

First resonance potential mean of $b-a$ and $d-c=2.65$ volts.

Second resonance potential mean of $c-a, d-b$, and $e-c=4.42$ volts.

Ionization potential $b-a+$ first resonance $=8.0$ volts.

The points of inflection on all the curves may be explained by the two resonance potentials given by the lines $1.5 S-2 p_{2}$ and I.5 $S-2 P$ of the different metals. The points $b^{\prime}$ given in the tables, but not in the curves, are the ionization points measured by the Lenard method. They correspond to the limiting frequencies I.5S. These metals give no further evidence of a third resonance potential, as was apparent in mercury under some 
conditions. The curve obtained in cadmium vapor, Fig. 2, is remarkably similar to the mercury curves; the curves of zinc and magnesium less so as the vapor pressure obtainable with these later metals was limited very much by the use of a Pyrex glass containing tube. As with mercury, no inflection was detected corresponding to a single inelastic collision at the second resonance potential except in calcium, indicated by $a^{\prime}$. The points corresponding to successive collisions, one of each type, and to two of one and one of the other, are distinct.

The experimental error shown in these results is somewhat less than with mercury in spite of the relative faintness of many of the points. The troublesome "overlapping" effects are not apparent. At the higher temperatures electric leaks become noticeable, and the use of four electrodes instead of three considerably magnifies the effect on current measurements. Table 5 gives a summary of the three critical potentials observed, the corresponding wave lengths in the spectrum and the theoretical values for the potentials deduced from the latter. The similarity of the spectra of strontium and barium to those of the other elements of this group justifies the prediction of their critical potentials. For the other two elements of this group, berylium and radium, spectral data are not available.

TABLE 5.-Critical Potentials and Spectral Lines in Metals of the Second Group

\begin{tabular}{|c|c|c|c|c|}
\hline 'Metal & $\begin{array}{l}\text { Series, Paschen } \\
\text { notation }\end{array}$ & $\begin{array}{l}\text { Wave length } \\
\mathbf{A} \text { in vac }\end{array}$ & $\begin{array}{l}\text { Computed } \\
\text { potential }\end{array}$ & $\begin{array}{l}\text { Observed } \\
\text { potential }\end{array}$ \\
\hline Zinc........ & $\begin{array}{l}a 1.5 \mathrm{~S} \\
1.5 \mathrm{~S}-2 \mathrm{p}_{2} \\
1.5 \mathrm{~S}-2 \mathrm{P}\end{array}$ & $\begin{array}{l}1319.98 \\
3076.88 \\
2139.33\end{array}$ & $\begin{array}{l}\text { 9. } 3524 \\
\text { 4. } 0122 \\
\text { 5. } 7705\end{array}$ & $\begin{array}{l}\text { 9. } 3 \\
4.18 \\
5.65\end{array}$ \\
\hline Cadmium...... & $\begin{array}{l}a 1.5 \mathrm{~S} \\
1.5 \mathrm{~S}-2 \mathrm{p}_{2} \\
1.5 \mathrm{~S}-2 \mathrm{P}\end{array}$ & $\begin{array}{l}1378.69 \\
3262.09 \\
2288.79\end{array}$ & $\begin{array}{l}8.9542 \\
\text { 3. } 7844 \\
5.3937\end{array}$ & $\begin{array}{l}\text { 9. } 0 \\
\text { 3. } 95 \\
\text { 5. } 35\end{array}$ \\
\hline Mercury......... & $\begin{array}{l}a 1.5 \mathrm{~S} \\
1.5 \mathrm{~S}-2 p_{2} \\
1.5 \mathrm{~S}-2 \mathrm{P}\end{array}$ & $\begin{array}{l}1187.96 \\
2537.48 \\
184960\end{array}$ & $\begin{array}{r}10.3918 \\
4.8651 \\
6.6744\end{array}$ & $\begin{array}{l}10.2 \\
4.76 \\
6.45\end{array}$ \\
\hline Magnesium......... & $\begin{array}{l}a 1.5 \mathrm{~S} \\
1.5 \mathrm{~S}-2 \mathrm{p}_{2} \\
1.5 \mathrm{~S}-2 \mathrm{P}\end{array}$ & $\begin{array}{l}1621.72 \\
4572.65 \\
2853.06\end{array}$ & $\begin{array}{l}7.6123 \\
2.6997 \\
\text { 4. } 3269\end{array}$ & $\begin{array}{l}\text { 8. } 0 \\
2.65 \\
4.42\end{array}$ \\
\hline Calcium..... & $\begin{array}{l}b 1.5 \mathrm{~S} \\
1.5 \mathrm{~S}-2 \mathrm{p}_{2} \\
1.5 \mathrm{~S}-2 \mathrm{P}\end{array}$ & $\begin{array}{l}2028.20 \\
6574.59 \\
4227.91\end{array}$ & $\begin{array}{l}6.0867 \\
1.8777 \\
2.9198\end{array}$ & $\begin{array}{r}c 6.01 \\
1.90 \\
2.85\end{array}$ \\
\hline Strontium... & $\begin{array}{l}b 1.5 \mathrm{~S} \\
1.5 \mathrm{~S}-2 \mathrm{p}_{2} \\
1.5 \mathrm{~S}-2 \mathrm{P}\end{array}$ & $\begin{array}{l}2176.94 \\
6894.45 \\
4608.61\end{array}$ & $\begin{array}{l}5.6708 \\
1.7906 \\
2.6787\end{array}$ & \\
\hline Barium....... & $\begin{array}{l}b 1.5 \mathrm{~S} \\
1.5 \mathrm{~S}-2 \mathrm{p}_{2} \\
1.5 \mathrm{~S}-2 \mathrm{P}\end{array}$ & $\begin{array}{l}2379.28 \\
7913.52 \\
5537.04\end{array}$ & $\begin{array}{l}5.1885 \\
1.5600 \\
2.2295\end{array}$ & \\
\hline
\end{tabular}

$a$ Dunz Tibingen dissertation. $b$ Data furnished by F. A. Saunders. $c$ Mohler, Foote, and Stimson. 
Scientific Papers of the Bureau of Standards, Vol. 16

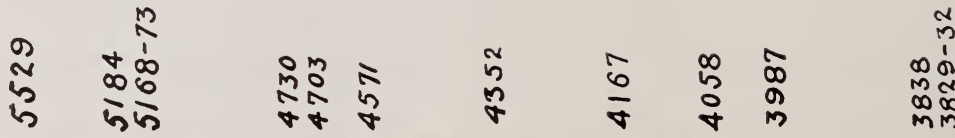

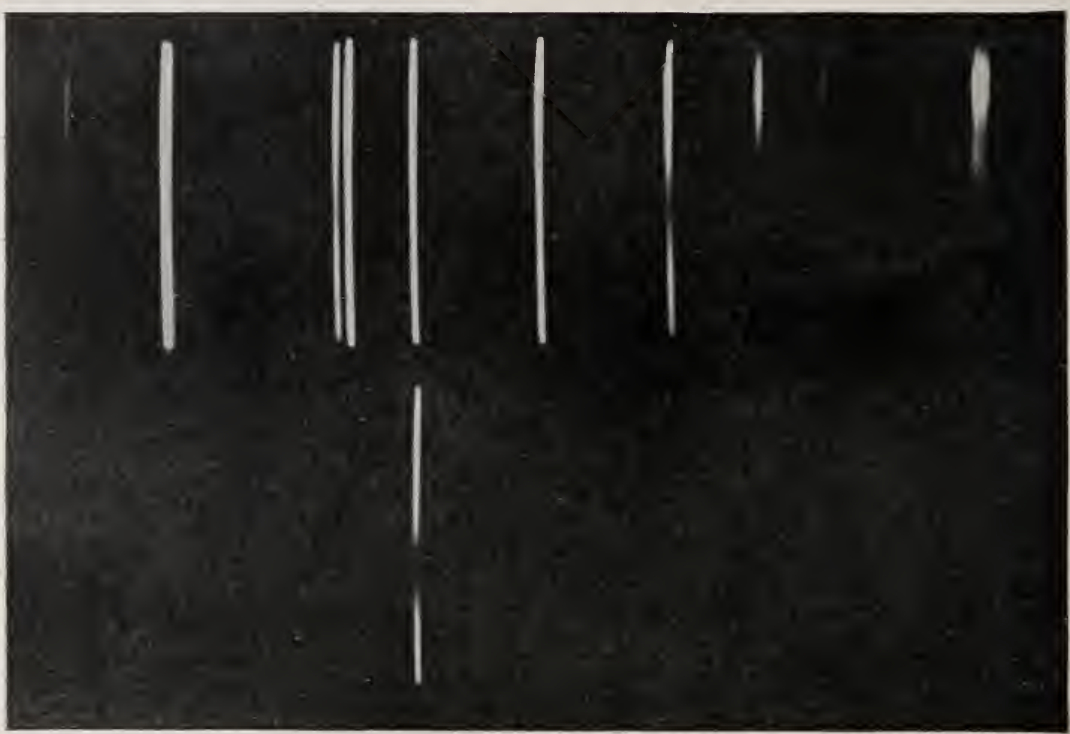

FIg. 3.- Spectra of magesium arc

Upper, 14 volts; lower, 3.5 volts showing the single line spectrum $\lambda=457 \mathrm{I}$ 


\section{LOW-VOLTAGE ARCS IN MAGNESIUM}

The correspondence as regards critical potentials and related spectral frequencies of all the metals of this group as shown by Table 5 emphasizes the difficulty raised in the results obtained by McLennan ${ }^{7}$ from his study of the low-voltage arc in magnesium. He observed the line I.5 $S-2 P, \lambda=2852$ A alone below the ionization potential, 7.6 volts. The plates published by McLennan suggested to the authors the possibility that his conclusion, that the line I.5 $S-2 p_{2}, \lambda=457$ I does not appear below this potential, was not justified. These plates show a strong continuous spectrum from the cathode throughout the visible region, and, while the line at $285^{2}$ is well outside of this region and shows clearly, a line of the same intensity at $\lambda=457 \mathrm{I}$ might have been entirely masked by the continuous background.

Our present work on the low-voltage arc has been limited to a study of the region transmitted by, glass, as the evidence for the existence of $\lambda=285^{2}$ below the ionization potential seems conclusive.

The vacuum tube was of Pyrex glass about $50 \mathrm{~cm}$ long and $2 \mathrm{~cm}$ in diameter. Electrodes consisting of a cylindrical anode surrounding a straight molybdenum wire cathode were sealed into one end of the tube, and a glass window was sealed with wax on the other end. The magnesium was boiled by a tube furnace about ${ }_{5} 5 \mathrm{~cm}$ long, which fitted around the electrode end of the vacuum tube. On account of the distance of the window from the furnace no trouble was experienced from magnesium distilling on it. The cathode was so placed that one of the lead wires shielded the direct light of the incandescent wire from the window. The light from the arc was brought to a focus on the slit of the spectrograph by a short focus lens, so that the glow discharge was viewed against the dark background of the far end of the tube.

Fig. 3 is a direct reproduction of a negative of two successive exposures. The upper spectrum is a five-minute exposure to the arc at I4 volts, the lower a four-hour exposure to the arc at 3.5 volts. The existence of $\lambda=457 \mathrm{I}$ as a single line spectrum is conclusively shown.

The experimental conditions were as follows: Temperature, $580^{\circ} \mathrm{C}$, current at $\mathrm{I} 4$ volts 5 milliamperes, current at 3.5 volts less than o.I milliampere. The glow decreased in brightness during the exposure, so that the ratio of exposure times is not a measure of the ratio of intensities. The break in the middle of 
some of the lines is the image of the spot that the lead wire of the cathode covered.

Overexposure of some of the arc lines masks the relative intensity as shown by some other plates obtained. The line at $\lambda=457 \mathrm{I}$ is much fainter than the arc lines on either side of it at $\mathrm{I}_{4}$ volts, so that the transition to the single line spectrum is most striking. The triplet $\lambda=5 \mathrm{I} 84-73-68$ is the strongest line just above the ionization potential, and many plates were obtained showing this line and $\lambda=457 \mathrm{I}$ alone. Under the experimental conditions there was a very large initial potential correction. The arc at 5 volts applied potential showed the triplet as well as $\lambda=457$ I distinctly, and it is safe to assume that there was then some ionization and that the actual potential was over 7.6 volts. If the triplet were a third low-voltage line, it would take a smaller potential to excite it than required for $\lambda=457 \mathrm{I}$, so that at the lower voltage it would appear in greater relative intensity, while the plate shows that it has entirely disappeared.

Detailed consideration of the 14 -volt arc spectrum is of some interest. Table 6 gives the series relations of the lines observed.

TABLE 6.-Lines Observed with 5-Minute Exposure to 14-Volt Magnesium Arc

\begin{tabular}{|c|c|c|c|c|c|}
\hline$\lambda$ in $A$ & $\begin{array}{c}\text { Series Paschen } \\
\text { notation }\end{array}$ & Remarks & $\lambda$ in $A$ & $\begin{array}{c}\text { Series Paschen } \\
\text { notation }\end{array}$ & Remarks \\
\hline $\begin{array}{l}4571 \ldots \ldots . \\
5184 \ldots \ldots . \\
5173 \ldots \ldots . \\
5168 \ldots \ldots \\
3838 \ldots \ldots \\
3832 \ldots \ldots \\
3829 \ldots \ldots \\
5529 \ldots \ldots \\
4703 \ldots \ldots \\
4352 \ldots \ldots \\
4167 \ldots \ldots \\
\end{array}$ & 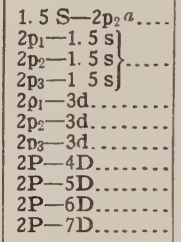 & $\begin{array}{l}\text { Low-voltage line } \\
\text { Predominant at ioniza- } \\
\text { tion point. }\end{array}$ & $\begin{array}{l}4058 \ldots . . \\
3987 \ldots . \\
3904 \ldots . \\
\\
5712 \ldots . \\
\\
4730 \ldots .\end{array}$ & $\begin{array}{l}2 \mathrm{P}-8 \mathrm{D} \ldots \ldots \\
2 \mathrm{P}-9 \mathrm{D} \ldots \ldots \\
2 \mathrm{P}-11 \mathrm{D} a \ldots \\
\\
\\
\end{array}$ & $\begin{array}{l}\text { Very faint and not } \\
\text { shown in reproduc- } \\
\text { tion. } \\
\text { Very faint and not } \\
\text { shown in reproduc- } \\
\text { tion. }\end{array}$ \\
\hline
\end{tabular}

$a$ The series relations are taken from Dunz ( $T$ übingen dissertations) except for these two lines, for which data we are indebted to Dr. F. A. Saunders.

A line listed by Saunders at $\lambda=3939,2 P-\mathrm{Io} D$ was not observed. It is significant, however, that in the region limited by the absorption of the flint-glass prism and the sensitivity of the ordinary photographic plate every magnesium "arc line" listed in Kayser and Runge has been photographed with a five-minute exposure. The possibilities of this type of source for a careful study of the single line and triplet series of magnesium is evident.

\section{CONCLUSION}

We may now safely make the following general statements of the phenomena of electron currents for all elements in the second 
column of the periodic table. There are three types of inelastic. impacts with molecules:

I. Above the first resonance potential a quantum of energy determined by the frequency I. $_{5} S-2 p_{2}$ may be lost by the electron and radiated as light of this wave length.

2. Above a second higher resonance potential corresponding to the frequency I. $5-2 P$ a corresponding quantum of energy may be transferred into this spectral line.

3. Above a potential given by the common limit $1.5 . S$ of the two series of which the above are the first lines the molecule is ionized by electron impact. The possibility that resonance potentials corresponding to higher terms of the absorption series exist is indicated, but not proven, by the results obtained in mercury. Collisions of these types must be at least very improbable and have little effect on the electron current.

Corresponding to the three types of collision we have three stages in the spectrum as the potential is increased. At the first resonance potential the corresponding line appears alone; above the second resonance point two lines appear, and at the ionization potential the entire arc spectrum appears. This spectrum can be probably entirely accounted for by the single line and triplet series systems, and except for the two low-voltage lines is ascribed to radiation emitted when ionized molecules recombine with electrons.

There are, however, a large number of enhanced spark lines including a system of doublet series which do not appear at all in the I4-volt arc. There must be, then, further transitions in the spectra of these metals occurring at higher potentials. A probable assumption is that there exists a second ionization potential corresponding to the work required to remove two electrons from a molecule (the two valence electrons) and that the spark spectrum arises when an electron recombines with the doubly charged ion.

The authors hope in the near future to investigate the problems suggested by this theory by methods similar to those here employed.

Washington, August I2, I920. 



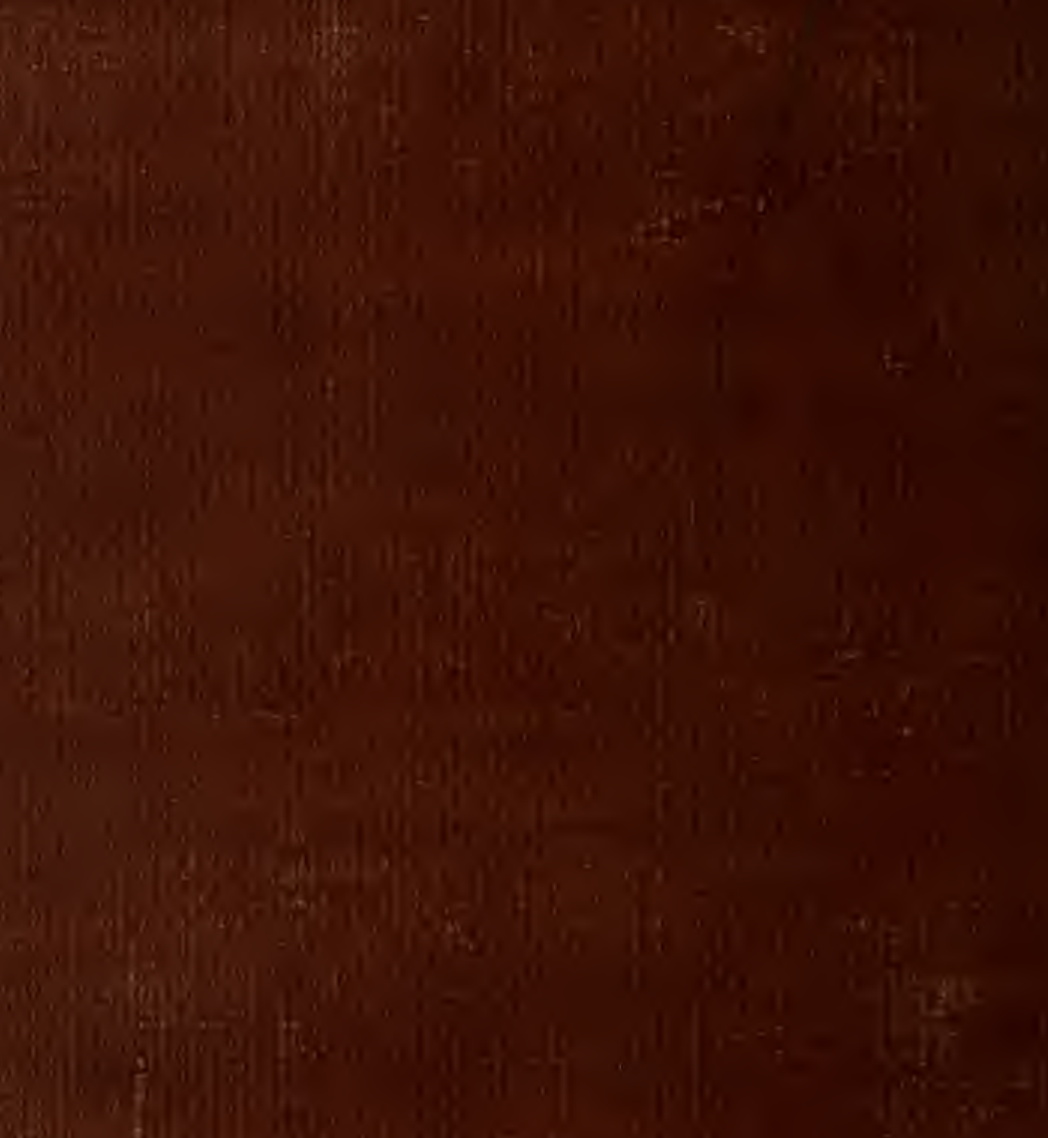